the treatment of refractory RA but experience with TNF- $\alpha$ antagonisers in JIA is limited.

Objectives We report the use of Infliximab in 3 patients with systemic JIA and polyarthritis.

Methods LS (18 yrs) and JD (11 yrs), girls with systemic-onset JIA at the age of 11 and 3, had persistent, destructive polyarthritis. AP (10 yrs), a boy with systemic-onset JIA at the age of 5 had persistent systemic activity as well as severe polyarthritis. All 3 failed NSAID, corticosteroids, (high-dose) MTX and CsA treatment and suffered from severe growth impairment and osteoporosis. All patients started Infliximab therapy at $3 \mathrm{mg} / \mathrm{kg}$ (weeks 0, 2, 6 and then 8-weekly). Active joint number (AJN), limited joint number (LJN), visual analogue scale for global well being (VASg) and pain (VASp), Childhood Health Assessment Questionnaire (CHAQ), serum CRP and serum IL-6 were assessed.

Results At present, LS completed 26, JD 38 and AP 86 treatment weeks. LS experienced a manifest decrease in AJN (17 to 1). LJN was unchanged (8). Functional scores decreased markedly: VASg 78 to 10 , VASp 45 to 10 , CHAQ 1.2 to 0.3 . CRP decreased ( 15 to $3 \mathrm{mg} / \mathrm{l}$ ) and steroids were tapered from 6 to 3 mg daily. JD showed a similar response: AJN and LJN decreased rapidly (38 to 5 and 41 to 7 ). VASg, VASp and CHAQ all dropped markedly: 50 to 15,50 to 10 and 2.1 to 1.4 . CRP and ESR decreased ( 22 to $5 \mathrm{mg} / \mathrm{L}$ and 51 to $26 \mathrm{~mm} / \mathrm{hr}$ ). Steroid dose was kept at $4 \mathrm{mg}$ daily. AP experienced a decrease in AJN (9 to 3 ) and in LJN (12 to 4 ) during the first 18 weeks. As systemic inflammation persisted, Infliximab dose was increased to 5, later to $10 \mathrm{mg} / \mathrm{kg}$. Whereas AJN and LJN decreased further to 0 and 2, systemic symptoms and the acute phase response persisted: CRP and ESR fluctuated (15-148 mg/l and 45 ? $183 \mathrm{~mm} / \mathrm{h}$, respectively). Functional scores varied and reflected the increasing discomfort of preexisting joint damage. Steroid dose was tapered from 12 to $7 \mathrm{mg}$ daily. Infliximab was safe and well tolerated in all 3 patients: possible adverse reactions were fever (AP, once) and upper respiratory tract infection (AP three, JD once). TNF- $\alpha$ blockade with Infliximab in these patients with systemic-onset polyarticular JIA induced a rapid, sustained control of polyarthritis, with concomitant improvement of function, global well being and pain and decrease in biochemical inflammation. Systemic inflammation, however, did not respond to TNF- $\alpha$ blockade. This was evident in patient AP whose articular disease clearly responded but who had a persistent acute phase response with persistently elevated levels of CRP and IL-6.

Conclusion Infliximab is promising for the treatment of JIA. The observed dissociation between response of articular and systemic disease indicates that different cytokine networks may operate in systemic and articular inflammation of JIA.

\section{SAT0107 YOUNG ADULTS WITH JUVENILE ARTHRITIS (JA) IN REMISSION ATTAIN IMPROVED NUTRITIONAL STATUS COMPARED WITH HEALTHY CONTROLS}

M Haugen, G Lien, B Flatø, Ø Førre. Center for Rheumatic Diseases, The National Hospital, Oslo, Norway

10.1136/annrheumdis-2001.500

\section{Background}

Objectives The purpose of the study was to compare nutritional status in adults with a history of JA with nutritional status in healthy subjects.
Methods All patients diagnosed with JA between 1980-1985 were re-investigated in 1997. Eighty-eight female patients and 51 male patients were $>20$ years of age and in remission at the time-point of investigation. Mean age was $25.2 \pm 2.8$ years in females and $25.0 \pm 3.0$ years in males. Mean age at disease debut was $9.7 \pm 3.2$ in the females and $10.1 \pm 3.4$ in the males. Median years (range) with active disease was 6.7 (0.3-25.1) in the female group and $3.3(0.1-15.5)$ in the male group. Fortyone healthy females (mean age $27.4 \pm 3.1$ years) and 54 healthy males (mean age $25.7 \pm 3.1$ years) were recruited from a military base in the Oslo area as controls. Total body lean body mass and body fat percentages were measured with DXA scanner (Lunar Expert). As laboratory measurements serum albumin concentration and haemoglobin concentrations were measured. Dietary intake was evaluated from a quantitative food frequency questionnaire.

Results While Body Mass Index (weight/height2) was similar in the two groups the subjects with a history of JA had significantly more lean mass than the healthy controls $(p<0.01$ for both females and males) and had significantly lower percentage of body fat ( $\mathrm{p}<0.001$ in both females and males). The subjects with a history of JA had a statistical significant higher concentration of haemoglobin $(p<0.001$ for the females and $p<0.05$ for the males) and serum albumin concentration ( $p<0.001$ for both) compared with the healthy controls. The patient groups had a higher energy intake per kilo body weight and fat intake than the control group, though this was only statistical significant in the male group $(\mathrm{p}<0,05)$. The frequency and amount of physical activity at the time-point of investigation was similar in the patients with a history of JA and the controls.

Conclusion Nutritional status in young adults with a history of JA does not seem to affected by disease during puberty, at least not negatively.

\section{SAT0108 UVEITIS AND ITS OUTCOME IN PATIENTS WITH JUVENILE IDIOPATHIC ARTHRITIS - LONG TERM STUDY}

${ }^{1} \mathrm{~K}$ Jarosova, ${ }^{2} \mathrm{D}$ Nemcova, ${ }^{1} \mathrm{~J}$ Vencovsky. ${ }^{1}$ Institute of Rheumatology; ${ }^{2}$ Department of Pediatrics, Charles University, Prague, Czech Republic

10.1136/annrheumdis-2001.501

\section{Background}

Objectives To determine the frequency of uveitis and its complications in patients with juvenile idiopathic arthritis (JIA).

Methods A retrospective analysis of 185 patients with JIA diagnosed between 1980 ? 1995 followed in 2 paediatric rheumatology centres. Patients with chronic and acute uveitis were identified in subgroups of JIA.

Results Uveitis was diagnosed in $24(13.0 \%)$ patients. Sixteen (8.6\%) patients had chronic and eight $(4.3 \%)$ had acute uveitis. Twelve $(75.0 \%)$ patients who developed chronic uveitis did so after the onset of arthritis, but only 8 within the first 7 years of JIA. There were four patients who developed chronic uveitis 9, 13, 14 and 17 years after JIA onset. Four patients who manifested arthritis after uveitis did so after $1,3,3$ and 6 years. Chronic uveitis was associated with systemic arthritis (in 17.6\%), persistent oligoarthritis (in 29.6\%), extended oligoarthritis (in 4,5\%), psoriatic arthritis (in 40\%) and other arthritis (in 14.3\%). Complications, such as synechiae, band keratopathy, cataract or glaucoma developed in $10(62.5 \%)$ patients with chronic uveitis. As expected, these were found mainly in patients with ANA positivity ( $\mathrm{n}=8 ; 80.0 \%$ ), in contrast to only 2 between ANA 
negative patients. Amaurosis was found in 7 patients; complete visual loss developed in one case.

Acute uveitis was seen only among arthritis+enthesitis patients $(\mathrm{n}=6 ; 10.7 \%)$ and in patients with other arthritis $(\mathrm{n}=$ 2; 14,3\%).

Conclusion Uveitis is relatively common in JIA. Chronic form may occur in several JIA subgroups, with persistent oligoarthritis patients and, surprisingly, with psoriatic arthritis patients being the most frequently affected. Acute uveitis is associated with HLA B27 associated disease forms. It is important to check for asymptomatic uveitis through the entire course of disease, as it may begin well after the onset of arthritis and may lead to severe complications.

Supported by grant NE/4879-3 from IGA of the Czech Ministry of Health.

\section{SAT0109 EXPRESSION OF BCL-2 IN JUVENILE CHRONIC ARTHRITIS}

${ }^{1}$ E Tuszkiewicz-Misztal, ${ }^{2} \mathrm{~A}$ Bojarska-Junak, ${ }^{2} \mathrm{P}$ Krawczyk, ${ }^{2} \mathrm{~J}$ Roliñski, 'V Opoka-Winiarska. ${ }^{1}$ Department of Paediatrics, Pulmonary Diseases and Rheumatology; ${ }^{2}$ Department of Clinical Immunology, Medical University, Lublin, Poland

\subsection{6/annrheumdis-2001.502}

Background The aim of this study was to investigate the relationship between levels of molecules regulating of apoptosis in $\mathrm{T}$ lymphocytes and the clinical manifestation of juvenile chronic arthritis (JCA).

Objectives Apoptosis is involved in the regulation of an immune response to foreign and autoantigens. We determined the expression of Bcl-2 mitochondrial oncoprotein, which inhibit apoptosis, in different subtypes of lymphocytes obtained from peripheral blood from healthy children $(\mathrm{n}=14$, age:12,4 \pm $5,4)$ and JCA patients with pauciarticular onset ( $\mathrm{n}=17$, age: $12,2 \pm 3,8)$ and polyarticular onset $(\mathrm{n}=30$, age: $11,8 \pm 3,2)$.

Methods All samples were analysed using monoclonal antibodies and flow cytometry technique.

Results Peripheral blood T lymphocytes from patients with pauciarticular onset JCA expressed a significantly lower amount of the $\mathrm{Bcl}-2$ protein than $\mathrm{T}$ lymphocytes from patients with polyarticular onset JCA $(\mathrm{p}<0,01)$ and healthy children $(\mathrm{p}<0,05)$. This differences concerned both $\mathrm{CD}^{+}$and $\mathrm{CD}^{+} \mathrm{T}$ cells but $\mathrm{CD} 4^{+}$lymphocytes expressed significantly $(\mathrm{p}<0,05)$ lower level of $\mathrm{Bcl}-2$ protein in comparison with $\mathrm{CD}^{+}$cells in patients with polyarticular onset JCA. There were no correlations between the expression of $\mathrm{Bcl}-2$ and the age of children in all subgroup of patients. There was significant positive correlation $(\mathrm{R}=0,562, \mathrm{p}<0,05)$ between the percentage of $\mathrm{T}$ lymphocytes with receptor for IL-2 (CD25) and expression of Bcl-2 protein in T cells in children with pauciarticular onset JCA.

Conclusion Our data supported the notion that disturbances in T cell apoptosis may play a role in the immunopathological processes leading to clinical manifestation of JCA, These data suggest also that both polyarticular onset and pauciarticular onset JCA have different pathogenesis and probably distinct aetiologies.
SAT0110 SOLUBLE ADHESION MOLECULES (ICAM-1, VCAM-1, ESELECTIN, P-SELECTIN) IN JUVENILE IDIOPATHIC ARTHRITIS AND CHILDHOOD - ONSET SCLERODERMA

${ }^{1}$ EK Musiej-Nowakowska, ${ }^{2}$ Sopata, ${ }^{2} \mathrm{~J}$ Wize, ${ }^{2} E$ Wojtecka-Lukasik, ${ }^{1} \mathrm{~A}$ Romicka, ${ }^{2} \mathrm{~S}$ Maslinski. 'Pediatric Clinic; ${ }^{2}$ Department of Biochemistry, Institute of Rheumatology, Warsaw, Poland

\subsection{6/annrheumdis-2001.503}

Background The soluble forms of adhesion molecules (sAM) may have a regulatory function in inflammatory responses and may serve as useful markers of both leukocyte and endothelial cells activation in different diseases, including several autoimmune disorders. They have been studied in adults with certain rheumatic diseases while studies in paediatric patients are more limited.

Objectives The aim of this study was to compare the levels of sAM in children with juvenile idiopathic arthritis (JIA) and scleroderma and to correlate serum levels of these molecules with conventional inflammatory parameters and to determine differences in these levels among clinical subtypes of JIA.

Methods Soluble forms of AM ICAM-1, VCAM-1, E-selectin and P-selectin were measured by sandwich ELISA in 47 children with JIA, (24 pauciarticular, 7 polyarticular, 16 systemic) and 11 patients with scleroderma. The levels of sAM according to type of disease, JIA type and some inflammatory parameters (ESR, total white blood cell count-WBC, platelet count) were analysed. Results Differences in serum levels of sAM have been demonstrated among the 3 subtypes of JIA. The highest values were seen in patients with systemic disease, lower values in patients with polyarthritis and pauciarticular form. The statistically significant higher levels of sICAM-1 $(\mathrm{p}<0.01)$ and sE-selectin $(\mathrm{p}<$ 0.05 ) were recorded only in JIA patients with systemic symptoms than in children who were pauciarticular. In systemic JIA, positive correlation was found between sICAM-1 as well as $\mathrm{sE}$ selectin levels and ESR and WBC. Levels of sICAM-1 and sEselectin were significantly higher in children with abnormal values of ESR versus patients with normal values $(p<0.05$ and $p$ $<0.05$, respectively). Similarly, significantly higher levels of sICAM-1, sE-selectin and sP-selectin were recorded in cases with higher number of WBC in comparison with others $(\mathrm{p}<0.05$, $\mathrm{p}$ $<0.025, \mathrm{p}<0.02$, respectively). In patients with scleroderma sE-selectin level was lower than in polyarticular form $(p<0.05)$ and the concentration of both sICAM-1 and sE-selectin were significantly lower than in systemic JIA ( $\mathrm{p}<0.05$ and $\mathrm{p}<0.05$, respectively). In contrast, sVCAM-1 levels were significantly higher only in scleroderma children in comparison with pauciarticular $(\mathrm{p}<0.02)$ and higer than in polyarticular and equal to the systemic group.

Conclusion The preliminary results indicate the role of sVCAM1 in the pathogenesis of childhood-onset scleroderma and confirm the differences between subtypes of JIA and suggest that sICAM-1 and sE-selectin may be another useful tool of monitoring the activity of systemic JIA.

\section{SAT0111 JUVENILE SYSTEMIC LUPUS ERYTHEMATOSUS IN PORTUGUESE CHILDREN}

W Castelão, H Canhão, C Resende, JE Fonseca, JC Teixeira Costa, JA Pereira Silva, M Viana Queiroz. Rheumatology Unit, Santa Maria Hospital, Lisbon, Portugal

10.1136/annrheumdis-2001.504 